\title{
Bilateral optic nerve sheath meningiomas in a patient with neurofibromatosis type 2
}

\author{
I A Cunliffe, D A Moffat, D G Hardy, A T Moore
}

\begin{abstract}
A 34-year-old woman who presented with hearing loss and tinnitus was found to have reduced vision bilaterally. Computed tomography scan revealed bilateral acoustic neuromas and bilateral optic nerve sheath meningiomas. The presence of bilateral acoustic neuromas fulfils the criteria for the diagnosis of central neurofibromatosis (neurofibromatosis type 2). Although this is the first report of bilateral optic nerve sheath meningioma in neurofibromatosis type 2, meningiomas are commoner in this dominantly inherited disorder, than in its absence and both forms of central nervous system tumour may be caused by loss of tumour suppressor genes on chromosome 22.
\end{abstract}

Addenbrooke's Hospital, Hills Road, Cambridge Department of Ophthalmology I A Cunliffe

A T Moore

Department of Neurootology

D A Moffat

D G Hardy

Correspondence to:

Mr A T Moore FRCS

Department of

Ophthalmology, Road, Cambridge CB2 2QQ.

Accepted for publication

31 October 1991

Figure 1 Photographs of optic discs showing bilateral pallor and mild swelling of the nerve fibre layer. $A$

Right disc. B: Left disc.

Optic nerve sheath meningiomas are uncommon, and though they may present at any age they are predominantly seen in middle aged females. They are unilateral in most cases. ${ }^{1-5}$ The usual presentation is with slowly progressive visual loss, and most patients have evidence of field loss and optic atrophy or disc swelling at presentation. ${ }^{1-5}$ Opticociliary shunt vessels are found on the optic disc in about $20 \%$ of cases. ${ }^{3}$ Other findings include mild axial proptosis, limited ocular movements, and gaze evoked amaurosis. ${ }^{5}$ Optic nerve meningiomas are thought to be more common in patients with neurofibromatosis than

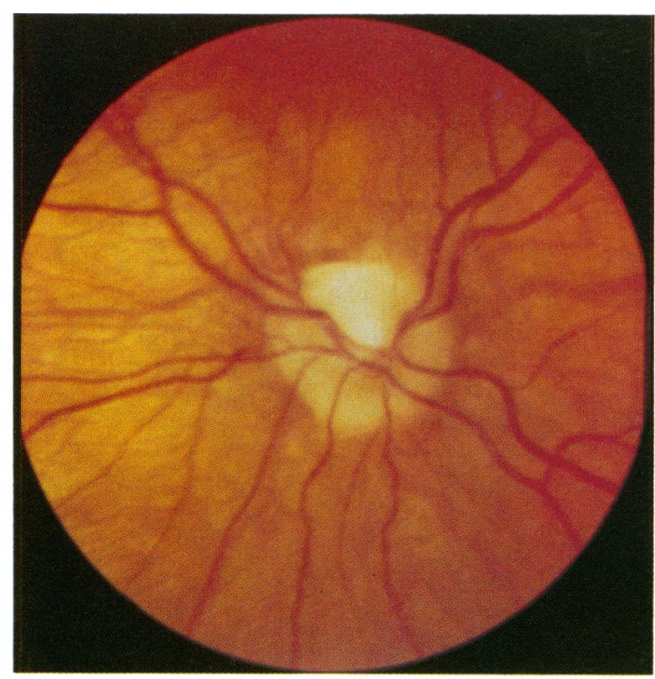

in general, ${ }^{12+}$ when they are usually unilateral. Bilateral optic nerve sheath meningiomas are rare and in none of the reported case $^{3-13}$ has there been any evidence of neurofibromatosis.

We report on a patient with neurofibromatosis (type 2) who had evidence of bilateral acoustic neuromas and bilateral optic nerve sheath meningiomas, causing a dual sensory impairment.

\section{Case report}

A 34-year-old woman presented with an 18month history of tinnitus, increasing deafness in the right ear, and numbness of the right cheek. She had been otherwise well and the only other relevant history was that she had a longstanding right convergent squint and associated amblyopia. She had undergone surgery for right

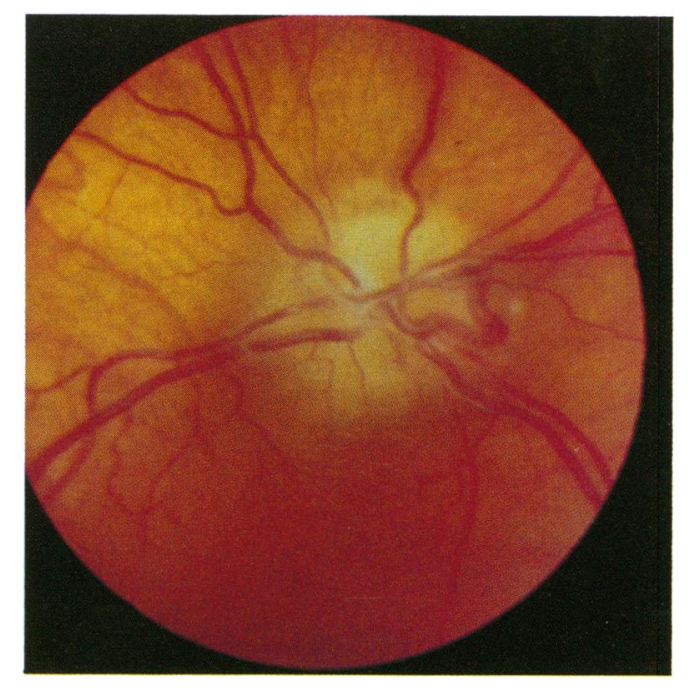
squint at age 7 years.

On examination she had reduced hearing in the right ear, reduced sensation in the distribution of the second division of the right trigeminal nerve, and evidence of mild ataxia. The visual acuity was counting fingers in the right eye and $6 / 6$ in the left eye. Colour vision testing with Ishihara plates was normal in the left eye, but she was unable to recognise any plates with the right. There was a $3 \mathrm{~mm}$ right proptosis, and a cover test revealed a small right divergent squint. Ocular movements of the right eye were full, but she had limitation of elevation, 


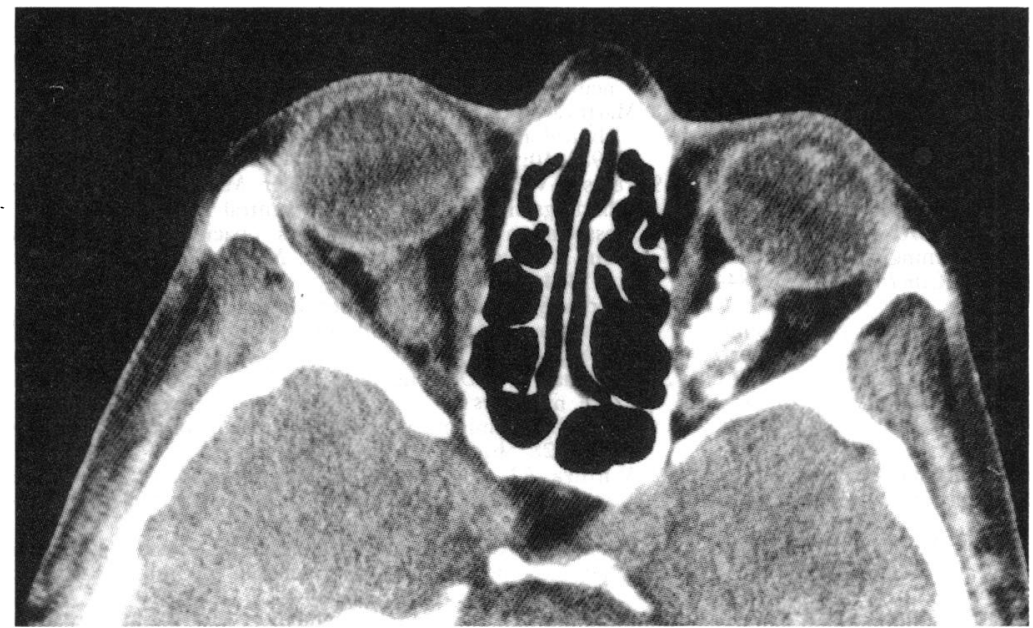

Figure 2 CT scan showing thickened calcified left optic nerve tumour and thickened irregular right optic nerve.

abduction, and adduction of the left eye. There was bilateral gaze-evoked nystagmus. Corneal sensation was reduced on the right but normal on the left. The lenses were clear, and intraocular pressures were normal. Both pupils reacted to light, and there was no relative afferent pupillary defect.

Slit-lamp examination of the iris was normal, with no evidence of Lisch nodules. Both optic discs were pale and slightly swollen but without any opticociliary shunt vessels (Figs 1A, B). In each eye there was a small slightly raised pale subretinal lesion, with associated fibrosis, lying temporal to the macula, probably representing a choroidal hamartoma. Goldmann perimetry revealed a dense right central scotoma and generalised constriction of the left visual field. Visual evoked potentials were unrecordable to both flash and pattern stimuli in the right eye. In the left eye the only abnormality was a mildly prolonged latency of the pattern VEP.

Computed tomography (CT) scan showed a large right acoustic neuroma and a small left acoustic neuroma. In addition there were bilateral optic nerve lesions. The left optic nerve showed a large calcified mass, and there was an enlarged irregular thickening of the right optic nerve, consistent with bilateral optic nerve sheath meningiomas (Fig 2). Systemic examination revealed no other evidence of neurofibromatosis, and there was no family history of hearing loss or central nervous system (CNS) tumours.

The right cerebellopontine angle tumour was excised via a translabyrinthine approach, and histological examination confirmed it to be a benign schwannoma. A postoperative magnetic resonance imaging scan showed the right tumour to have been completely excised and confirmed the presence of biiateral optic nerve tumours with no evidence of chiasmal involvement.

\section{Discussion}

The neurofibromatoses are divided into two distinct disorders: neurofibromatosis 1 (Recklinghausen's disease, NF1) and neurofibromatosis 2 (bilateral acoustic neurofibromatosis, NF2). Both are inherited as autosomal dominant traits with a high degree of penetrance. The genes responsible for each type have been mapped, to chromosome 17 for NF1 and chromosome 22 for
NF2. ${ }^{1+}$ The diagnostic criteria for each disorder are given in the Neurofibromatosis Conference Statement. ${ }^{15}$ The criteria for NF2 are met if the patient has (1) bilateral eighth nerve masses, or (2) a first degree relative with neurofibromatosis 2 and either a unilateral eighth nerve mass, or two of the following: neurofibroma, meningioma, glioma, schwannoma, or juvenile posterior subcapsular lens opacity. The patient reported here fulfils the criteria for the diagnosis of NF2.

Patients with NF2 typically present with either unilateral or bilateral hearing loss, and most have evidence of disturbed vestibular function. ${ }^{16-18}$ Large tumours may involve lower cranial nerves or result in raised intracranial pressure. ${ }^{16}$ The ophthalmic manifestations include juvenile posterior subcapsular lens opacities, ${ }^{19}$ corneal abnormalities associated with loss of corneal sensation or seventh nerve palsies, papilloedema from raised intracranial pressure, nystagmus, sixth nerve palsy, and less commonly visual pathway tumours as in this case. In contrast to NF1 Lisch nodules are rarely present. ${ }^{20}$ In NF2 there is an increased incidence of other central nervous system tumours, which may be of schwann cell, glial, or meningeal origin. ${ }^{16} 182122$

Although the mechanism of tumour formation is uncertain, similarities with the development of non-ocular tumours in the hereditary form of retinoblastoma suggest that there may be loss of tumour suppressor genes in NF2. Acoustic neuromas (like retinoblastoma), occur in a hereditary and non-hereditary form. ${ }^{1+}$ Patients with the non-hereditary form have unilateral tumours which present later, and do not develop other CNS tumours. In patients with NF2 there is often a family history, the tumours are bilateral and present earlier and there is an increased risk of developing other CNS tumours, particularly meningioma. Both meningiomas and acoustic neuromas $^{2324}$ show loss of chromosome 22 material in the tumour tissue, suggesting that in patients with NF2 (who have a germinal mutation of chromosome 22) tumour formation may result from the loss of the normal allele as a result of a somatic cell mutation..$^{24}$ It is unclear, however, whether the mutations responsible for acoustic neuromas and meningiomas are at the same or different loci on chromosome 22.25 Although unilateral optic nerve meningiomas have been reported in neurofibromatosis, ${ }^{13+26}$ most reports predate the recognition of the two forms of the disorder, and it is not clear whether these optic nerve tumours are seen predominantly in peripheral or central NF. In the family with NF2 reported by Delleman et $a l^{21}$ one affected member had a unilateral optic nerve sheath meningioma but without acoustic neuroma. The patient reported here is further evidence that optic nerve sheath meningiomas may develop in NF2 and may result from the loss of normal genes responsible for regulating growth of neural tissues. intraorbital meningiomas. Arch Ophthalmol 1974; 91: 24-8. 2 Wilson WB. Meningiomas. Arch anterior visual svstem. Sur Ophthalmol 1981; 26: 109-27.

3 Sibony P, Krauss HR, Kennerdell JS, Maroon JC, Slamovit TL. Optic nerve sheath meningiomas. Clinical manifestations. Ophthalmology 1984; 91: 1313-26.

4 Jakobiec FA, Depot MJ, Kennerdell JS, et al. Combined clinical and computed tomographic diagnosis of orbital glioma and meningioma. Ophthalmologv 1984; 91: 137-55. 
5 Sarkies NJC. Optic nerve sheath meningioma: diagnostic . Eye 1987; 1: 597-602. 6 Craig WM, Gogela LJ. Meningioma of the optic foramen as cause of slowly progressive blindness. Report of three cases. J Neurosurg 1950; 7: 44-8.

7 Salazar JL, Bauer J, Frenkel M, Sugar O. Bilateral optic cana meningioma. Surg Neurol 1977; 8: $11-4$

8 Trobe JD, Glaser JS, Post JD, et al. Bilateral optic canal meningiomas. A case report. Neurosurgery 1978; 3: 68-74.

9 Hollenhurst RW, Hollenhurst RW, MacCarty CS. Visua prognosis of optic nerve sheath meningiomas producing shunt vessels on the optic disk. Mayo Clin Proc 1978; 53: 84 92.

10 Hirst LW, Miller NR, Allen GS. Sphenoidal pneumosinus dilatans with bilateral optic nerve meningiomas. Case report f Neurosurg 1979; 51 : 402-7.

11 Hart WM, Burde RM, Klingele TG, Perlmutter JC. Bilatera optic nerve sheath meningiomas. Arch Ophthalmol 1980; 98 149-51.

12 Liano H, Garcia-Alix C, Lousa M, Marquez M, Nombela L, De Miguel J. Bilateral optic nerve meningioma. Case report. Eur Neurol 1982; 21; 102-6.

13 Kennerdell JS, Maroon JC, Malton M, Warren FA. The management of optic nerve sheath meningiomas. Am Ophthalmol 1988; 106: 450-7.

14 Mulvhill JJ. Neurofibromatosis 1 (Recklinghausen disease) and neurofibromatosis 2 (bilateral acoustic neurofibromatosis). An update. Ann Intern Med 1990; 113: 39 52 .

15 Neurofibromatosis Conference Statement. National Institute of Health Consensus Development Conference. Arch Neurol 1988; 45: 575-8.

16 Young DF, Eldridge R, Gardner WJ. Bilateral acoustic neuroma in a large kindred. $\mathcal{F A M A} 1970 ; 214 ; 347-53$.
17 Kanter WR, Eldridge R, Fabricant R, Allen JC, Koerber T. Central neurofibromatosis with bilateral acoustic neuroma: genetic, clinical and biochemical distinctions from peripheral neurofibromatosis. Neurology 1980; 30: 851-9.

18 Martuza RL, Ojemann RG. Bilateral acoustic neuromas: clinical aspects, pathogenesis, and treatment. Neurosurgery 1982; 10: 1-12.

19 Pearson-Webb MA, Kaiser-Kupfer MI, Eldridge R. Eye findings in bilateral acoustic (central neurofibromatosis): 作 but absence of Lisch nodules. $N$ Engl F Med 1986; 315: $1553-4$.

20 Charles SJ, Moore AT, Yates JRW. Ferguson-Smith MA. Lisch nodules in neurofibromatosis type 2. Arch Ophthalmol 1989; 107: 1571-2.

21 Delleman JW, De Jong JGY, Bleeker GM. Meningiomas in five members of a family over two generations, in one member simultaneously with acoustic neuromas. Neurology 1978; 28: $567-70$.

22 Martuza RL, Eldridge R. Neurofibromatosis 2 (bilateral acoustic neurofibromatosis). N Englf Med 1988; 318: 684 8.

23 Seizinger BR. Martuza RL, Gusella JF. Loss of genes on chromosome 22 in tumorigenesis of human acoustic neuroma. Nature 1986; 322: 644-7.

24 Seizinger BR, Rouleau G, Ozelius LJ, et al. Common pathogenic mechanisms for three tumour types in bilateral accoustic neurofibromatosis. Science 1987; 236: 317-9.

25 Dumanski JP, Rouleau GA, Nordenskjold M, Collins VP. Molecular genetic analysis of chromosome 22 in 81 cases of meningioma. Cancer Res 1990; 50: 5863-7.

26 Cibis GW, Whittaker CK, Wood WE Intraocular extension of optic nerve meningioma in a case of neurofibromatosis. Arch Ophthalmol 1985; 103: 404-6. 